\title{
Structure, Capacity or Power? Explaining Salience in EU Decision-Making*
}

\author{
DIRK LEUFFEN, THOMAS MALANG and SEBASTIAN WÖRLE \\ University of Konstanz
}

\begin{abstract}
Salience as the intensity of interest is a key explanatory factor of European Union decision-making. In this article, the ability of three explanatory models to explain the realized values of Member States' salience is hypothesized and tested. On the basis of the DEU II data, the analysis shows that a mixture of national interest group heterogeneity and membership length has the highest predictive power. The results support the liberal intergovernmentalist claim that domestic interests determine European decision-making.
\end{abstract}

\section{Introduction}

Salience is a core concept of political analysis. For instance, it features prominently in models of vote choice, public opinion research, interest group politics, and formal and informal models of political decision-making. In this article, we analyze salience formation in the European Union (EU). In particular, we seek the driving forces behind Member State saliences in Council decision-making. Thus, while in most research salience is used as an independent variable, we here address it as a dependent variable.

Our theoretical argument for explaining salience builds on liberal theories of European integration and Member State preference formation. In such a perspective, state saliences result from societal demands that are voiced by interest groups to then be aggregated by administrative and governmental agents. In the theoretical part of the article, we separate two parts of this liberal account - the societal and the administrative parts - into two sets of explanations. The first relates to 'structure'; the second to 'capacity'. In addition, we control for a realist argument that links salience to power and EU-level factors.

We empirically test our theoretical claims on the newly published DEU II data set (Thomson et al., 2012). Regression analyses reveal that two factors stand out as strongly driving a Member State's overall salience in EU decision-making. First, interest group mobilization - captured in our analysis by the number of national interest groups active in Brussels - matters. Second, a country's experience with the political system of the EU seems to be an important factor for explaining saliences; in particular, we find that the salience levels of those Member States that acceded to the EU in the two rounds of eastern enlargement clearly fall below the levels of most elder Member States. The 'length of membership' effect is no longer present for the states that acceded to the EU in 1994 in the

* The authors would like to thank Wim van Aken, Richard Rose, Arndt Wonka, the anonymous reviewers and Amy Verdun for their helpful comments, Robin Hertz for providing the Shapley-Shubik index data for the EU-27, and Tobias Tober for his research assistance. 
so-called 'EFTA enlargement'. We take this finding, in addition to the observed difference between Bulgaria and Romania and the other new Member States, as evidence for a steep adjustment curve. In contrast, power indicators, in our analysis, do not display strong explanatory effects.

The article is structured as follows: after introducing the concept of 'salience' and its use in decision-making analyses, we develop a set of theoretical expectations on salience formation in EU decision-making. We then briefly introduce our data and methods before engaging in the actual analysis. We run OLS regressions on DEU II data on the state level before investigating the dynamics on the level of an individual policy area. In particular, we test our model on a subset of issues relating to the common fisheries policy (CFP). We conclude by discussing our findings and formulating some suggestions for future research.

\section{Salience: A Concept and Its Implications}

There is a general agreement that salience is important for analyzing politics. At the same time, the meaning of salience is more contested. For example, Wlezien (2005, p. 557) deplores that salience is not properly defined in large parts of the literature: 'There thus is little consensus about what the word means: It means different things to different people and nothing in particular at all to others'. Warntjen (2012) provides a useful review of the literature. He identifies relative and absolute understandings of salience, retrospective as distinct from contemporary salience (cf. also Mayhew, 1991; Netjes and Binnema, 2007), salience as related to policy or electoral impact (for example, Netjes and Binnema [2007, p. 40] summarize their definition of salience as the "extent to which the party leadership considers an issue as vital for its electoral appeal'), different levels of salience (policy-field-, proposal- or issues-related salience), and finally different actors such as states, ministries, parties or electorates that are considered important subjects in salience analysis.

In this article we follow a definition of salience introduced by Thomson and Stokman (2006), closely related to a similar understanding of the concept by Achen (2006). Thomson and Stokman (2006, pp. 41ff.) distinguish two interpretations of salience used in bargaining models:

In the first, salience is interpreted as the proportion of an actor's potential capabilities it is willing to mobilize in attempts to influence the decision outcome. In the second, salience is understood as the extent to which actors experience utility loss from the occurrence of decision outcomes that differ from the decision outcomes they most favour.

The first definition has a relational and a behavioural component. 'Relational' since capabilities are limited and any investment in one issue should imply fewer resources to be spent on other issues. 'Behavioural' because mobilizing capabilities in EU decisionmaking means that an actor should become active in EU negotiations. In contrast, the second definition does not contain any reference to behaviour. It relates to an idea of a 'true salience'. At the same time, the two understandings are related since a strongly weighted utility loss should incite actors to become more active in inter-state bargaining. Also in our measurement we cannot exclude that our experts evaluate an issue's salience for a particular country on this country's or its representatives' behaviour in the Council or its working groups. Since the second definition is analytically more fundamental as it 
predefines the conditions for the behavioural expectations of the first definition, we prefer to stick to this purer notion of salience. Very generally, we follow Thomson et al. (2006, 2012 , p. 612) and many others who use the term synonymously with 'importance' or 'intensity' (cf. Achen, 2006; Warntjen, 2012, p. 169). Salience:

describes the sharpness in the curvature of [an] actor's loss function. Actors who attach high levels of salience to an issue are highly sensitive to small deviations from their most favoured positions, while actors who attach low levels of salience are less sensitive. (Thomson and Stokman, 2006, p. 42)

As stated above, salience is a key component of decision analyses (cf. Golub, 2012; Schneider et al., 2010). Achen (2006, p. 92) succinctly reviews the literature underlining the importance of 'intensity' to influence in decision-making and traces an intellectual history going back at least to Arthur Fisher Bentley's 'Process of Government' of 1908 (Bentley, 1908; cf. also Warntjen, 2012). Building on this tradition of institutional realism, in the well-known compromise model proposed by Van den Bos (1991) and theoretically further developed by Achen (2006) salience or 'intensity' is the second influence or weight factor besides power in a decision analysis. Salience also is a key component of exchange or logrolling models (cf. König and Junge, 2009). For example, Coleman (1990, pp. 850, 866) incorporates salience in his model as 'strength of interests'. Similarly, in König and Proksch's (2006, p. 211) procedural exchange model 'saliencies are an indicator for an actor's relative interest in the multiple issues of a Commission proposal'. Thus salience seems important for explaining decision-making processes and outcomes. It is 'conceptually and empirically distinct from actors' policy positions' (Thomson, 2011, p. 47) and it informs about the intensity or the level of interest actors hold in a negotiation.

\section{Theorizing Salience Formation in EU Decision-Making}

What accounts for the level of salience that countries hold in EU decision-making? Despite the uncontested relevance of the concept we know surprisingly little about salience formation in EU decision-making. On the basis of Warntjen's (2012, p. 169) distinction between actor- and issue-specific components, we can formulate two questions:

- What determines the overall level of salience that different EU Member States attach to contested EU policy issues?

- What explains different levels of salience across different issues and issue areas in EU policy-making?

Generally, we assume that the overall salience varies across countries as well as issues. In this article, however, we concentrate on answering the first question. The phenomenon to be explained is the overall salience of Member States across diverse policy issues. It is hardly imaginable that a country exists that has either the highest interest in every policy issue that is debated on the European level or no interest at all. Most countries should fall between these extreme poles. But should they all hold similar levels of overall salience? Or is it likely that some countries have higher levels of salience than others? More analytically, which factors should affect the saliences that countries hold in EU negotiations? 
Our theory of salience in EU decision-making builds on a liberal intergovernmentalist framework (Moravcsik, 1993, 1998). In the first step of this framework, called 'preference formation', societal groups articulate their demands and put pressure on their governments. Re-election-seeking governments then aggregate these societal demands to defend them in inter-state bargaining. Societal interests thus are key drivers of national preferences, and accordingly, the intensity of these preferences - that is, their salience - should also be driven by societal interests. Societal demand, in turn, should be determined by the economic structure of a state, linked to the costs and benefits of economic interdependence. At the same time, societal demands are not sufficient for explaining Member State preferences and their salience. While the demands are usually voiced by interest groups, they must also be taken up by governmental agents that represent the state at the European level. Interest mobilization and governmental organization should thus jointly determine states' positions and saliences in EU decision-making. Our first set of hypotheses accordingly relates to the economic structure of countries and interest group mobilization. The second set of hypotheses relates to state capacity, defined as the ability of states and their administration to receive, administer and promote these societal interests on the European level.

Finally, as a control, a third set of factors will be hypothesized relating to systemic factors that might affect national saliences. In order to account for systemic factors, often accentuated in neo-realist international relations theory, our empirical analysis will control for power and budgetary contributions. While such factors are more strongly related to the behavioural dimension of salience, we still think that we should include them into our analysis both because of the prominent usage of the behavioural definition of salience in the literature and because this permits us to empirically test the construct validity of our measurement (cf. Adcock and Collier, 2001). In other words, if these 'power' variables are not significant, we are more confident that we, in fact, measure 'true' saliences. In the following we will introduce these three sets of explanations in more detail, summarized as 'structure', 'capacity' and 'power'.

\section{Structure/Interest Diversity}

Moravcsik (1993, 1998) presents a liberal theory of national preference formation. Domestic societal actors voice their demands and expectations and thereby influence governmental actors. For Moravcsik (1993, p. 483) the:

most fundamental influences on foreign policy are [. . . ] the identity of important societal groups, the nature of their interests, and their relative influence on domestic policy. Groups that stand to gain and lose a great deal per capita tend to be the most influential. The identity, interests, and influence of groups vary across time, place and, especially, issue-area, according to the net expected costs and benefits of potential foreign policies.

Governments thus aggregate the preferences articulated by groups and '[ $\mathrm{f}]$ or liberals, the relationship between society and the government is assumed to be one of principal-agent' (Moravcsik, 1993, p. 483).

Per definition, issue salience reflects the intensity of actors' policy positions (Thomson et al., 2012, p. 612). We follow Achen (2006) and others who link the issue of salience to the sharpness in the curvature of an actor's loss function; that means to costs. From a liberal intergovernmentalist perspective, costs are ultimately borne by societal actors (Moravcsik, 1993, 1998). Politicians, in turn, care for their re-election (cf. Downs, 1957). 
They therefore have electoral incentives to satisfy societal demands and this also holds for European politics. Liberal intergovernmentalism's focus on different societal groups suggests that governments should care particularly about satisfying the demand of active and powerful groups in society. Groups that actively follow and screen European policymaking are more likely to impose costs on governments if their policy demands are not well 'looked after' than more silent groups. This is where diversity and mobilization come into play. States with a less diversified interest structure should have a lower overall level of salience in EU decision-making as compared to states with a more diversified economic and societal structure. While Luxembourg might have strong saliences concerning financial regulation but might be less interested in issues relating to the CFP, German representatives might be interested in both, the banking sector as well as fisheries. Accordingly, we hypothesize that the range of economic societal interests should affect the overall level of salience that states hold in EU decision-making.

H1: The broader the range of (economic) interests of a state, the larger the overall salience of this state in EU negotiations.

In the literature, diversity has also been linked to state size. All else being equal, smaller states should be less diversified than larger states. For example, Arregui and Thomson (2009, p. 672) suggest that small states typically have less diversified economies as a result of which a narrower range of regulatory proposals affect their interests. This consideration forms the basis of our second hypothesis:

H2: The larger a state, the more diverse its interests should be and accordingly its relative size of salience in EU decision-making.

\section{Capacity}

The literature on interest group politics increasingly stresses the importance of information supply as a means for interest group influence (Klüver, 2011, 2012). However, to be effective, information also needs to be processed by those to whom it is addressed. This is related to an administration's capacity. How capable is a national administration in satisfying societal demands? Thus while a country's economic structure might be rather diversified and complex, state capacity could be insufficient for successfully administering different societal demands. Following a liberal understanding of politics, we do not consider national interests and - linked to this - saliences of preferences to be predetermined, but rather understand them to result from political processes and interactions. Therefore, a position that might objectively be considered important does not matter as long as it does not obtain importance in the domestic game. Part of this is the administrative capacity.

Two different reasons for a limited administrative capacity are conceivable. First, poorer states might not be able to finance a large and highly qualified administration in their Brussels' representations and their national ministries. Lack of resources might thus limit the expertise which is needed to promote a state's interests. Panke (2010) has identified this resource constraint as a concern for small states in EU policy-making. Limited capacities can thus require a small state to prioritize a few selected issues (Panke, 2011); a tactic also observed in international negotiations outside the EU (Thorhallsson, 2010). Alternatively, a lack of capacity can lead to an overall limited engagement in EU 
policy-making (Panke, 2011). In both cases, the overall level of saliences that are manifested in the European arena should be smaller than in more efficient or capable states.

Second, one could imagine that expertise needs to grow over time. Administrations of newly acceded Member States might still be in the learning phase. They either need to learn the 'Brussels game' (that is, the way decisions are being taken in the EU) or they need to develop a stronger expertise on the policy issues that are debated in Brussels (see also Cross, 2012, p. 54). Oftentimes, the complexity of EU policy issues makes the assessment of the consequences of EU legislation a matter that is being far from straightforward. If the impact of EU legislation cannot satisfactorily be evaluated by an administration, it is likely that a state should take less pronounced positions in EU law-making. This should negatively affect the saliences of the specific country. A lack of capacity thus acts as a constraint for saliences.

H3: The smaller the administrative capacities of a state, the smaller the overall salience levels in EU decision-making.

H4: The longer a state is a member of the EU, the higher its overall salience levels.

\section{Power}

$\mathrm{H} 1$ to $\mathrm{H} 4$ relate to domestic factors of salience formation. However, this liberal reading might be criticized from a neo-realist perspective that would stress the importance of systemic factors. In particular, power is generally considered an important factor for explaining political decision-making (Schure and Verdun, 2008). In the EU Council, different Member States have a different number of votes under qualified majority voting (QMV) rules. At the same time, power not only concerns size and is related to this voting power, but also economic factors (for which we will also control in the empirical analysis). But how should power affect state saliences? In the behavioural definition discussed above, salience was interpreted as the proportion of an actor's potential capabilities it is willing to mobilize in attempts to influence the decision outcome. In line with this, a powerful state should be able to mobilize more capabilities than a weaker state. A weaker state accordingly should concentrate its efforts on issues that are of the highest concern to it. And a weak state that defends all issues with a high intensity is likely to lose credibility from its partners. In contrast, a more powerful state can formulate stronger claims on more issues.

H5: The more powerful a state in EU decision-making, the higher its overall level of salience.

An alternative EU-level explanation is more materialist. It follows on Carrubba's (1997) and others' idea that the EU resembles a market in which states trade liberal policy preferences against financial subsidies. In such a perspective, net recipient states should be 'silenced' and, in turn, abstain from active participation in EU law-making. Thus their low saliences are bought by the net contributors.

H6: The more a state pays into the EU budget, the higher its overall level of salience should be.

In the following we will detail our operationalization and introduce our data and methods before engaging in the empirical analysis. 


\section{Operationalization, Methods and Data}

The literature proposes and discusses different measures for salience (cf. Warntjen, 2012). Literature on voting behaviour usually draws on survey items such as the 'most important problem' question (cf. Niemi and Bartels, 1985; Wlezien, 2005). Others have used quantitative or qualitative text analysis or media coverage (for example, Epstein and Segal, 2000; Mahoney, 2007). Again others draw on expert surveys or party manifesto data (cf. Netjes and Binnema, 2007). In our analysis we use expert interviews. According to Warntjen (2012, p. 168): 'Expert interviews provide the most fine-grained and least ambiguous measure but are costly to conduct for a large number of proposals'.

Fortunately, we were able to draw on the DEU II data set (cf. Thomson et al., 2012) for the operationalization of our dependent variable - the salience of Member States in EU decision-making. The data set contains information on 331 controversial issues raised by 125 legislative proposals that were introduced between 1996 and 2008. ${ }^{1}$ While the data set covers the positions and the saliences on these issues of all EU Member States (at the time of law-making), the Commission and the European Parliament, we here only focus on Member States' saliences. The information was recorded during 349 semi-structured interviews with experts mostly from national representations in Brussels as well as from the Commission and the European Parliament. Since the procedure used to assemble this data set, the case selection strategy, the interview techniques and validity and reliability tests are explained in detail in Thomson et al. $(2006,2012)$, we can concentrate here on detailing the measurement of saliences.

The interview partners were asked to identify the salience held by each stakeholder (that is, country) on each controversial issue after the introduction of the proposal and before the Council formulated its common position. The scale for measuring salience was defined to range from 0 to 100 . The scale was introduced in the interviews as follows:

Stakeholders differ from each other in the salience or importance they attach to issues. For example, a particular issue may be of great importance to one stakeholder but only marginal to another. Please estimate the salience each stakeholder attaches to each issue on a scale from 0 to 100 . A score of 100 indicates that an issue is of the highest importance to a stakeholder, while a score of zero indicates that the issue is of no importance whatsoever to a stakeholder. A score of 50 indicates that the issue has an average level of priority for the stakeholder concerned, and that it is willing to use arguments but not power politics to convince opponents. Note that it is possible for a stakeholder to attach a high level of salience to an issue on which it takes a moderate position, and a low level of salience to an issue on which it takes an extreme position. (Thomson et al., 2012, p. 613)

Since in our theory we are interested in overall levels of salience, we aggregated the information of the 331 issues in order to calculate the average salience each country held over all the issues contained in the data set. ${ }^{2}$ In order to control for possible larger changes

\footnotetext{
${ }^{1}$ As to the composition of the data set Thomson et al. (2012, p. 608) report that: 'The selection contains a high proportion of legislative proposals from the areas of Agriculture (26), Internal Market (18), Justice and Home Affairs (11) and Fisheries (14). However, many other policy areas are present too, which allows us to examine the extent to which patterns in inputs, processes and outputs can be generalized across different policy areas'.

${ }^{2}$ Note that in the data set it was assumed that a country had a salience of 0 for an issue whenever the interview partners were unable to point out a position for a country and there was no salience level recorded for the particular country. Thus, only if both salience and position were missing the salience was coded 0 .
} 
Figure 1: Overall Means and Predicted Values for Each Country in the Study

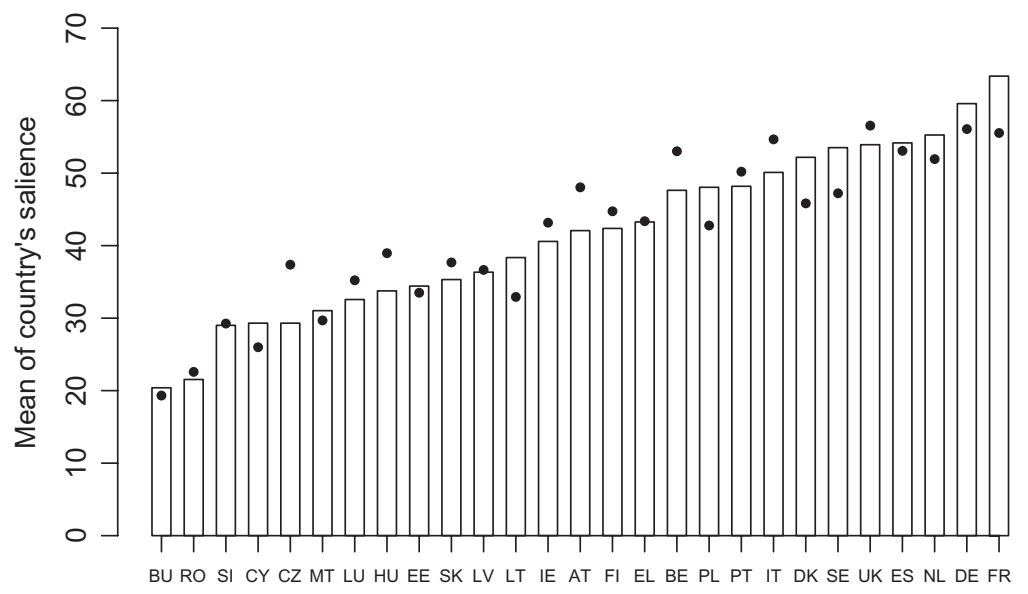

Source: Authors' own calculations.

that impacted on EU decision-making following eastern enlargement we only use those issues in our analysis that were decided in the EU-25 and EU-27. We thus calculate the means for 157 issues passed after 2004. ${ }^{3}$ The overall mean for each country is presented in Figure 1. We see that mean saliences vary between 63 (France) and 20 (Bulgaria), and the average over all 27 Member States is 41 (with a standard deviation of 12 points) on our scale ranging from 0 to 100 . All countries have attached at least one 0 or 100 points to one issue or the other.

\section{Structure/Interest Diversity}

The explanatory variables are analogously operationalized and measured on the country level. The descriptive statistics for all variables can be found in Table 1. The most promising proxy for the interest diversity of a country, in our opinion, is the number of registered interest groups at the European level. We take the most encompassing database of interest group size and scope per country as introduced by Wonka et al. (2010). This data set combines three different sources: the Commission's CONECCS database, the European Parliament's accreditation register and Landmarks' 'European Public Affairs Directory'. We assume that the more registered interest groups from a country are present in Brussels, the more diversified a national economy. The explanatory variable for the second hypothesis - state size - is measured by the overall population in $2010 .{ }^{4}$

\section{Capacity}

A state's capacity to develop a certain level of salience on the European level is largely determined by the expertise a national government can generate about a specific policy.

\footnotetext{
${ }^{3}$ These are the issues $174-331$ of the DEU II data set. Of course, the issues passed before 2007 were not included when calculating the mean values for Bulgaria and Romania, which only became EU members in 2007.

${ }^{4}$ Taken from Eurostat: «http://epp.eurostat.ec.europa.eu/portal/page/portal/eurostat/home/».
} 
Table 1: Variable Description

\begin{tabular}{lcllll}
\hline Variable & Observations & Mean & Standard deviation & Minimum & Maximum \\
\hline Mean salience & 27 & 41.69 & 11.50 & 20.39 & 63.38 \\
Interest groups & 27 & 67.52 & 104 & 2 & 380 \\
Population & 27 & $18.6 \mathrm{Mio}$ & $23.4 \mathrm{Mio}$ & 414,372 & $81.8 \mathrm{Mio}$ \\
Administrative capacity & 27 & 72.44 & 23.67 & 31 & 138 \\
Shapley Shubik & 27 & 0.02 & 0.01 & 0.004 & 0.05 \\
Payment in \% GNI & 27 & 1.13 & 1.6 & -0.41 & 5.03 \\
GDP per capita & 27 & 23655 & 15746 & 4800 & 79500 \\
Salience Fishery & 27 & 31.76 & 21.36 & 0 & 68.91 \\
IG Fishery & 27 & 10.85 & 16.94 & 0 & 64 \\
Coastline & 27 & 2511 & 3769 & 0 & 13676 \\
\hline
\end{tabular}

Source: Authors' own calculations.

We assume that Member States vary in their ability to process information provided by societal actors. In EU negotiations in Brussels, the permanent representations of the Member States and the committee of permanent representatives (Coreper) play a central role. We therefore take the number of permanent administrative experts that reside for every country in the Coreper as a measure for a state's administrative capacity in EU politics. Numbers of staff in the year 2010 are taken from Peterson and Shackleton (2012).

Specific policy information is only one facet of a nation's capacity to act. According to Panke (2011), another factor is the knowledge of and socialization in the complex environment of EU decision-making. The maturity of a country as a member of the EU can be seen as an additional factor that influences salience formation. Thus, the general length of membership could be considered as an indicator of a country's experience with EU decision-making. However, we assume that learning the rules of the game should only take a few years. We do not expect a capacity difference between, for instance, the United Kingdom and France due to the fact that the former entered the European Community about 15 years later than the latter. Therefore, we decided to test for the effects of the latest two enlargement rounds, which clearly divide the EU-15 from the 12 new Member States. Additionally, we controlled for the latest enlargement round with a dummy for Bulgaria and Romania with the aim of capturing the differences between the latest Member States.

\section{Power}

To operationalize the realist argument of power as a core factor in political decisionmaking (Dahl, 1961), we concentrate on the different voting weights of Member States in the Council of the EU. A common way is to use the Shapley-Shubik index. Originally formulated by Shapley and Shubik (1954), this index understands power as a country's ability to form successful winning coalitions. High values mean a high critical power to form such a coalition, low values indicate a low potential to do so. The second variable we consider important for the power-centred explanation is financial capacity, as measured by monetary flows from and to the EU. Net contributors should be in a better position to form strong saliences than net receivers as the latter would be compensated by financial 
transfers as side-payments and would attach less importance to the negotiated issue. Measurement of these transfers has been - both politically and academically - disputed. We operationalize this variable as the net monetary transfer a country receives in relation to its gross national income (GNI) (see also Carrubba, 1997; Garry and Tilley, 2009). We use data from the European Commission's 2010 budget financial report (European Commission, 2011, Annex 2c). Net transfers range from -0.41 per cent in the case of Belgium, the relatively largest net contributor, to Lithuania, which receives more than 5 per cent of its GNI as net payments. We control for GDP per capita in our final model to safeguard against a country's potential economic power, independent of its area or population. We take 2010 data from Eurostat. ${ }^{5}$

\section{Empirical Analysis}

\section{Overall Salience}

The quantitative empirical analysis is computed by running ordinary least square regressions. This method faces one problem in our study: since there are only $27 \mathrm{Member}$ States at the moment, and an increase of observations through the addition of a temporal dimension was not possible, we have a very limited number of cases. Therefore, we kept our different models very parsimonious. First, we run different models for our different explanatory blocks, thereby sorting out the weak explanatory factors. Next, we introduce a combined model, which contains the strongest explanatory factors. ${ }^{6}$

Some of our independent variables are not normally distributed. We transformed these variables to a symmetric distribution to meet the OLS assumptions. Thus, our study contains the logged version of the number of interest groups per country, GDP per capita and population and the reciprocal root of the Shapley-Shubik index.

The first block of explanations focuses on a country's economic structure. The first hypothesis expects that a broader range of economic interests in a state has a positive effect on the overall level of salience. The second hypothesis expects that larger states have higher saliences because of a more diversified economic structure, ceteris paribus. Column 1 of Table 2 indicates that the number of interest groups, indeed, positively impacts salience formation. The more national interest groups present in Brussels, the higher a state's overall salience. In contrast, population size does not increase overall salience when we control for the number of interest groups. Country size as such does not seem to matter.

Our second set of arguments relates to administrative capacities. Column 2 of Table 2 underlines that both capacity indicators - administrative capacity as measured by the number of EU permanent representatives of a country $(H 3)$ and the experience as measured by enlargement rounds $(\mathrm{H} 4)$ - show significant correlations in the hypothesized directions. But the learning effect is much stronger and more robust than the quantity of administrative

\footnotetext{
${ }^{5}$ We do not take average values to avoid problems with currency exchange rates or measurement divergences. Generally speaking, the 2010 data are very similar to a $2007-10$ average.

${ }^{6}$ We generally think that multicollinearity is not a big problem for our analysis. In the presence of such multicollinearity standard errors are inflated, which leads to more conservative interpretations of an estimate's significance. However, to be cautious about the potential influences on the substantive results and a check on the robustness of the main results, we did a variance inflation factor analysis (VIF) after the calculation of our full model. Only GDP per capita has a value that could be of concern. However, since the exclusion of the GDP variable does not change the results, we are quite confident that multicollinearity is indeed an issue of little concern in our analysis.
} 
Table 2: Regression Results for Overall Salience

\begin{tabular}{lcccc}
\hline & $\begin{array}{c}\text { Functional } \\
(1)\end{array}$ & $\begin{array}{c}\text { Capacity } \\
(2)\end{array}$ & $\begin{array}{c}\text { Power } \\
(3)\end{array}$ & $\begin{array}{c}\text { Full } \\
(4)\end{array}$ \\
\hline Log Interest Group & $5.770^{* * *}(1.17)$ & & & $3.756^{* *}(1.45)$ \\
Log Population & $-0.0749(1.35)$ & & & $-0.0116(0.07)$ \\
Administrative capacity & & $0.135^{* *}(0.06)$ & & $-14.34 * *(4.83)$ \\
Enlargement 2004 & & $-15.39^{* * *}(2.91)$ & & $-0.433(1.30)$ \\
Payment in \% of GNI & & $-1.325^{*}(1.14)$ & $0.0160(0.81)$ \\
Shapley Shubik & & & & $-9.489^{*}(5.13)$ \\
Log GDP per capita & & & & $-19.84^{* * *(5.78)}$ \\
Enlargement 2007 & $25.57(19.02)$ & $38.75^{* * *}(5.19)$ & $60.11^{* * *}(5.07)$ & $133.1 * *(51.19)$ \\
Constant & 27 & 27 & 27 & 27 \\
Observations & 0.68 & 0.60 & 0.41 & 0.82 \\
Adjusted $\mathrm{R}^{2}$ & & & \\
\hline
\end{tabular}

Source: Authors' own calculations.

Notes: Standard errors in parentheses. * $\mathrm{p}<0.10 ; * * \mathrm{p}<0.05 ; * * * \mathrm{p}<0.01$.

staff in Brussels. Especially when we compare the former EFTA states with the latest member countries, Romania and Bulgaria, we see that duration of membership has a strong effect on the level of overall saliences.

A third explanatory factor, power, was included into the analysis to control for systemlevel effects on Member State saliences. The power of the purse, measured through countries' European net payments, shows almost no statistically significant effect. Countries that pay more on average do not have consistently higher saliences than net recipients. In contrast, factual political power as measured through the Shapley-Shubik index is in line with the expectations of $\mathrm{H6}{ }^{7}$ Powerful states can develop higher salience over diverse issues. Whether this result is really because of power dynamics or rather is related to state size and economic diversity - the two variables are closely linked - cannot be answered here.

Finally, we combine all significant variables of the three models in order to distil the most robust explanations. In a nutshell, interest group heterogeneity and time of accession best explain the level of Member State saliences. Column 4 of Table 2 shows that the effect of the number of administrative staff is washed away in the full model. At the same time, eastern enlargement still has a strong effect in the expected direction. This partly rehabilitates the capacity argument and points to a learning potential. In contrast, the effect of the power hypotheses vanishes completely. Political power as well as the power of the purse has no effect on the overall levels of salience.

Considering the very high explained variance of the combined model (adjusted $\mathrm{R}^{2}=0.82$ ), the findings of the full model are straightforward. Given information about a Member State's interest group population and its time of EU accession, one can quite precisely predict the mean level of its salience. A strong presence of interest groups in Brussels and EU experience are at the basis for high levels of salience in EU decision-making.

\footnotetext{
${ }^{7}$ The negative effect is related to the transformation 'inverse square root'. Since the Shapley-Shubik index has realized values from 0.04 to 0.46 , the real effect is positive.
} 
A closer look at the point estimates per country gives further insights. These are visualized in Figure 1 by black points as compared to the realized values in the bars. For eight countries, our prediction is almost identical to the realized values. The Czech Republic, Belgium and Austria are the countries with the largest overestimation, whereas five countries have smaller predicted saliences as compared to their measured realizations. Overall we see no grave outlier.

So far, we have only studied salience at the aggregate level of policy areas, but are our findings robust when we disaggregate our data to individual policy areas?

\section{Issue-Specific Salience: The Case of the Common Fisheries Policy}

If our claim that national interest group representation has a strong effect on the level of salience is correct, the mechanism should also work for individual policy areas. To illuminate the relationship in more detail, we take one policy field that should deliver straightforward results for the disaggregated test of our model: the common fisheries policy meets this criterion. It is possible to distinguish clearly between countries that should develop a high salience in fishery due to their economic structure whereas other countries should not. Countries with no coastline will hardly have a fishing industry and, hence, fewer interest groups related to fishery. Therefore, these countries will not assign a strong importance to such policy issues. In contrast, European countries whose economy relies heavily on fishery should have stronger interest groups and a higher salience. Unlike other issue areas (internal affairs, energy or agriculture), fishery is not so encompassing that it attracts many diffuse interest groups. Instead it is a narrow issue area with an interest to particularistic groups. This is important for the theoretical argument, but also for coding data, since it is hardly possible to catch all relevant interest groups in a diffuse issue area. The case of the CFP is an important test for our argument. Since the case seems straightforward - and therefore illustrative - a negative finding has the potential to discard our argument. In other words, if the argument does not work in the case of the CFP, there is no need to continue analyzing other policy areas. Thus while CFP is not a crucial case for 'proving' our argument, it could be crucial for falsifying it (cf. Eckstein, 2000; Gerring, 2007). Therefore it seems well suited for our purposes.

We replicate our analysis with a new dependent variable 'salience in fishery policy' (Table 3). ${ }^{8}$ In addition, we had to replace the overall number of interest groups with issue-specific interest groups by country. Because such data were not readily available, we extracted the interest groups concerned with EU fishery policy from the EU transparency register. ${ }^{9}$ We also include coastal kilometres into our analysis as a more direct measure of economic structure. ${ }^{10}$

The results for CFP reinforce our initial argument. Both the number of fisheries-related interest groups and the accession date that we theoretically related to capacity have a strong and stable effect on countries' saliences in CFP decisions. The other explanatory

\footnotetext{
${ }^{8}$ We selected all DEU II issues related in their title to the CFP from the post-2004 period. In total, we identified seven proposals with 24 issues.

${ }_{9}^{9} \mathrm{Cf}$. «http://ec.europa.eu/transparencyregister/public/consultation/search.do\#searchResult». In our coding we included only interest groups that declare an interest in fisheries and additionally have their office in the respective countries (and not in Brussels). In order to meet the OLS requirements, we used the square root of the number of fisheries-related interest groups per country.

${ }^{10}$ Taken from the CIA World Factbook: «https://www.cia.gov/library/publications/the-world-factbook/fields/2060.html».
} 
Table 3: Regression Results for Fishery Salience

\begin{tabular}{|c|c|c|c|c|}
\hline & $\begin{array}{c}\text { Functional } \\
\text { (1) }\end{array}$ & $\begin{array}{c}\text { Capacity } \\
\text { (2) }\end{array}$ & $\begin{array}{l}\text { Power } \\
\text { (3) }\end{array}$ & $\begin{array}{l}\text { Full } \\
\text { (4) }\end{array}$ \\
\hline Interest Group Fish & $5.973 * * *(1.49)$ & & & $3.771 * *(1.78)$ \\
\hline Coastline & $0.00108(0.00)$ & & & \\
\hline Administrative capacity & & $0.121(0.14)$ & & \\
\hline Enlargement 2004 & & $-26.27 * * *(6.62)$ & & $-40.65 * * *(11.97)$ \\
\hline Payment in $\%$ of GNI & & & $-2.186(2.37)$ & \\
\hline Shapley Shubik & & & $-3.308^{* *}(1.20)$ & $0.484(1.24)$ \\
\hline Log GDP per capita & & & & $-25.40 * * *(8.55)$ \\
\hline Enlargement 2007 & & & & $-35.04 * * *(11.19)$ \\
\hline Constant & $14.36^{* * *}(4.44)$ & $34.70 * * *(11.81)$ & $62.93 * * *(10.51)$ & $289.5 * * *(86.13)$ \\
\hline Observations & 27 & 27 & 27 & 27 \\
\hline Adjusted $\mathrm{R}^{2}$ & 0.49 & 0.40 & 0.26 & 0.68 \\
\hline
\end{tabular}

Source: Authors' own calculations.

Notes: Standard errors in parentheses. $* \mathrm{p}<0.10$; ** $\mathrm{p}<0.05 ; * * * \mathrm{p}<0.01$.

variables do not change remarkably between the previous analysis and the disaggregated one. ${ }^{11}$ The explanatory power of the full model, represented in the adjusted $\mathrm{R}^{2}$ of 0.68 , stays reasonably high. These results increase the confidence in our argument. As stated above, we cannot infer from these results that the model will work in a similar manner for all issue areas. However, we believe that further testing of other issue areas will support rather than falsify our claims.

\section{Discussion of Results}

When we come back and refocus on the general question of the article - the explanation of a Member State's overall salience - we can see that the two most stable factors belong to two different sets of explanations that fit into a liberal paradigm. First, the results show that interest diversity and mobilization affect national saliences in EU decision-making. National representatives respond to societal demands; the more present and, per assumption, alert the interest groups, the higher the overall saliences of a country. The CFP example shows that this argument can also be adapted for specific issue areas: the strength of national organized interest in one policy field affects the level of salience a state has in these issues on a European level. Second, the findings about capacity show that a certain maturity or experience with the EU's institutional set-up is a necessary condition for developing overall high saliences. In this perspective, the 12 new Member States are still constrained in their capacity to form high saliences over a broad range of issues.

In our view, interest diversity is an important condition for the development of a high mean salience. Countries with a very narrow range of economic and social interests despite high capacities should have no reason to develop high mean saliences simply because there is little societal demand for actively engaging in some issues on the negotiation table. For example, even if Luxembourg could afford expertise on fishery, why

\footnotetext{
${ }^{11}$ Also adding 'population' does not substantively change these results.
} 
should it be interested in this policy field without societal interest? However, the interest heterogeneity of a country is insufficient to predict the mean salience of a country. Additionally, capacity is needed. Both conditions - the existence of strong societal demands and administrative capacity - jointly explain overall high levels of salience in EU decision-making.

The liberal reading that domestic factors determine the behaviour of decision-makers and their salience formation is contested by realist theory. Here, the importance of power-related factors is hypothesized as an explanation of actor behaviour. However, we find no convincing results in our analysis that power is systematically and robustly linked to salience. This finding has wider implications for our conceptual discussion on salience. We find no empirical evidence that supports the behavioural or strategic dimension of salience. The phenomenon that a state tries to boost its negotiation success by artificially augmenting its salience on issues cannot be observed.

\section{Conclusions}

In this article we have analyzed salience formation in EU decision-making. Theoretically, our argument builds on liberal intergovernmentalism. We claim that societal demands are at the basis of Member State saliences. At the same time, societal demands need to be processed by administrative and governmental actors. Accordingly, high overall saliences are based on strong societal demands, administrative capacity and experience. A third set of factors that we test in our article draws on realism and relates to power issues. We test our theoretical expectations on the DEU II data set. The analysis strengthens the liberal understanding of salience formation. On an aggregate policy level and on issues relating to the CFP, interest group presence seems to strongly impact national saliences. In addition, administrative experience, as captured by the duration of EU membership, seems to have an impact on salience formulation. In particular, the two latest newcomers at the time of writing, Romania and Bulgaria, display very low levels of overall saliences. Similarly, the countries that acceded to the EU in 2004, on average, have lower levels of salience than the old EU Member States.

Future research should pursue further disaggregation. Here we only analyzed overall saliences and issues relating to the CFP. Analyses on the level of other policy areas including more policy-specific variables - should allow for a more nuanced understanding of salience formation in EU Member States. In addition, qualitative case studies might further add to our understanding of the mechanisms of salience formation in selected issue areas and countries.

\section{Correspondence:}

Dirk Leuffen

Department of Politics and Public Administration

University of Konstanz

POB 83

Universitätsstraße 10

78457 Konstanz

Germany

email: dirk.leuffen@uni-konstanz.de 


\section{References}

Achen, C.H. (2006) 'Institutional Realism and Bargaining Models'. In Thomson, R., Stokman, F.N., Achen, C.H. and König, T. (eds).

Adcock, R. and Collier, D. (2001) 'Measurement Validity: A Shared Standard for Qualitative and Quantitative Research'. American Political Science Review, Vol. 95, No. 3, pp. 529-45.

Arregui, J. and Thomson, R. (2009) 'States' Bargaining Success in the European Union'. Journal of European Public Policy, Vol. 16, No. 5, pp. 655-76.

Bentley, A.F. (1908) The Process of Government (Cambridge, MA: Belknap Press).

Carrubba, C.J. (1997) 'Net Financial Transfers in the European Union: Who Gets What and Why?' Journal of Politics, Vol. 59, No. 2, pp. 469-96.

Coleman, J.S. (1990) Foundations of Social Theory (Cambridge, MA: Belknap Press).

Cross, J.P. (2012) 'Interventions and Negotiation in the Council of Ministers of the European Union'. European Union Politics, Vol. 13, No. 1, pp. 47-69.

Dahl, R.A. (1961) Who Governs? Democracy and Power in an American City (New Haven, CT: Yale University Press).

Downs, A. (1957) An Economic Theory of Democracy (New York: Harper \& Row).

Eckstein, H. (2000) 'Case Study and Theory in Political Science'. In Gomm, R., Hammersley, M. and Foster, P. (eds) Case Study Method (London: Sage).

Epstein, L. and Segal, J.A. (2000) 'Measuring Issue Salience'. American Journal of Political Science, Vol. 44, No. 1, pp. 66-83.

European Commission (2011) EU Budget 2010: Financial Report. Available at: «http://ec.europa .eu/budget/library/biblio/publications/2010/fin_report/fin_report_10_en.pdf».

Garry, J. and Tilley, J. (2009) 'The Macroeconomic Factors Conditioning the Impact of Identity on Attitudes towards the EU'. European Union Politics, Vol. 10, No. 3, pp. 361-79.

Gerring, J. (2007) Case Study Research: Principles and Practices (New York: Cambridge University Press).

Golub, J. (2012) 'How the European Union Does not Work: National Bargaining Success in the Council of Ministers'. Journal of European Public Policy, Vol. 19, No. 9, pp. 12941315.

Klüver, H. (2011) 'The Contextual Nature of Lobbying: Explaining Lobbying Success in the European Union'. European Union Politics, Vol. 12, No. 4, pp. 483-506.

Klüver, H. (2012) 'Informational Lobbying in the European Union: The Effect of Organisational Characteristics'. West European Politics, Vol. 35, No. 3, pp. 491-510.

König, T. and Junge, D. (2009) 'Why Don't Veto Players Use Their Power?' European Union Politics, Vol. 10, No. 4, pp. 507-34.

König, T. and Proksch, S.O. (2006) ‘A Procedural Exchange Model of EU Legislative Politics'. In Thomson, R., Stokman, F.N., Achen, C.H. and König, T. (eds).

Mahoney, C. (2007) 'Lobbying Success in the United States and the European Union'. Journal of Public Policy, Vol. 27, No. 1, pp. 35-56.

Mayhew, D.R. (1991) Divided We Govern: Party Control, Lawmaking and Investigations, 19461990 (New Haven, CT: Yale University Press).

Moravcsik, A. (1993) 'Preferences and Power in the European Community: A Liberal Intergovernmentalist Approach'. JCMS, Vol. 31, No. 4, pp. 473-524.

Moravcsik, A. (1998) The Choice for Europe: Social Purpose and State Power from Messina to Maastricht (Ithaca, NY: Cornell University Press).

Netjes, C.E. and Binnema, H.A. (2007) 'The Salience of the European Integration Issue: Three Data Sources Compared'. Electoral Studies, Vol. 26, No. 1, pp. 39-49.

Niemi, R.G. and Bartels, L.M. (1985) 'New Measures of Issue Salience: An Evaluation'. Journal of Politics, Vol. 47, No. 4, pp. 1212-20. 
Panke, D. (2010) 'Small States in the European Union: Structural Disadvantages in EU PolicyMaking and Counter-Strategies'. Journal of European Public Policy, Vol. 17, No. 6, pp. 799-817.

Panke, D. (2011) 'Small States in EU Negotiations: Political Dwarfs or Power-Brokers?' Cooperation and Conflict, Vol. 46, pp. 123-43.

Peterson, J. and Shackleton, M. (2012) The Institutions of the European Union (Oxford: Oxford University Press).

Schneider, G., Finke, D. and Bailer, S. (2010) 'Bargaining Power in the European Union: An Evaluation of Competing Game-Theoretic Models'. Political Studies, Vol. 58, No. 1, pp. $85-103$.

Schure, P. and Verdun, A. (2008) 'Legislative Bargaining in the European Union: The Divide between Large and Small Member States'. European Union Politics, Vol. 9, No. 4, pp. 460-88.

Shapley, L.S. and Shubik, M. (1954) 'A Method for Evaluating the Distribution of Power in a Committee System'. American Political Science Review, Vol. 48, No. 3, pp. 787-92.

Thomson, R. (2011) Resolving Controversy in the European Union: Legislative Decision-Making before and after Enlargement (Cambridge: Cambridge University Press).

Thomson, R., Arregui, J., Leuffen, D., Costello, R., Cross, J., Hertz, R. and Jensen, T. (2012) 'A New Dataset on Decision-Making in the European Union before and after the 2004 and 2007 Enlargements (DEUII)'. Journal of European Public Policy, Vol. 19, No. 4, pp. 604-22.

Thomson, R. and Stokman, F.N. (2006) Research Design: Measuring Actors' Positions, Saliences and Capabilities'. In Thomson, R., Stokman, F.N., Achen, C.H. and König, T. (eds).

Thomson, R., Stokman, F.N., Achen, C.H. and König, T. (eds) (2006) The European Union Decides (Cambridge: Cambridge University Press).

Thorhallsson, B. (2010) 'Small States in the UN Security Council: Means of Influence?' Hague Journal of Diplomacy, Vol. 7, No. 2, pp. 135-60.

Van den Bos, J.M.M. (1991) Dutch EC Policy Making: A Model-Guided Approach to Coordination and Negotiation (Amsterdam: Thela Thesis).

Warntjen, A. (2012) 'Measuring Salience in EU Legislative Politics'. European Union Politics, Vol. 13, No. 1, pp. 168-82.

Wlezien, C. (2005) 'On the Salience of Political Issues: The Problem with "Most Important Problem"'. Electoral Studies, Vol. 24, No. 4, pp. 555-79.

Wonka, A., Baumgartner, F.R., Mahoney, C. and Berkhout, J. (2010) 'Measuring the Size and Scope of the EU Interest Group Population'. European Union Politics, Vol. 11, No. 3, pp. 463-76. 